\title{
ANÁLISE DO CRESCIMENTO DE MUDAS DE JATOBÁ (Hymenaea courbaril L.) EM DIFERENTES NÍVEIS DE ÁGUA NO SOLO ${ }^{1}$
}

\author{
Hugo Henrique Costa do Nascimento², Rejane Jurema Mansur Custódio Nogueira ${ }^{3}$, Elizamar Ciríaco da
} Silva $^{4}$ e Marcelle Almeida da Silva ${ }^{2}$

\begin{abstract}
RESUMO - O objetivo deste trabalho foi analisar o crescimento de mudas de jatobá (Hymenaea courbaril L.) sob déficit hídrico. As plantas foram cultivadas em vasos contendo $8 \mathrm{~kg}$ de solo oriundo do local de coleta das sementes. Foram utilizados blocos casualizados como delineamento experimental, com quatro tratamentos hídricos (100\%, 75\%, 50\% e $25 \%$ da capacidade de pote) e seis repetições. Semanalmente foram avaliados a altura das plantas, o número de folhas e o diâmetro do caule. No final do período experimental, foram determinados a área foliar, a razão de área foliar e a área foliar específica, a produção de matéria seca das folhas, do caule, das raízes e total, e a alocação de biomassa para as folhas, o caule e as raízes. Verificou-se que o déficit hídrico afetou o crescimento das plantas quanto à altura, ao diâmetro do caule e à produção de matéria seca para os diversos órgãos, quando cultivadas em níveis a partir de $50 \%$ da CP. O número de folhas reduziu-se em todos os níveis de estresse, quando comparados com o tratamento $100 \%$ da CP. O padrão de alocação de biomassa, a relação raiz/parte aérea, razão de área foliar e área foliar específica, mas, não foram afetados pelo estresse. O número de folhas foi a variável mais sensível ao estresse. Mudas de jatobá não paralisaram o seu crescimento quando cultivadas com baixa disponibilidade de água no solo, na fase inicial do desenvolvimento. No entanto, seu crescimento foi severamente afetado em níveis de água abaixo de 50\% da capacidade de retenção de água no solo.
\end{abstract}

Palavras-chave: Crescimento, Déficit hídrico, Matéria seca e Relação raiz/parte aérea.

\section{JATOBA (Hymenaea courbaril L.) SEEDLING GROWTH ANALYSIS AT DIFFERENT WATER LEVELS IN THE SOIL}

\begin{abstract}
The objective of the present work was to analyze growth of jatoba (Hymenaea courbaril L.) seedlings under water deficit. Seedlings were grown in in vases with $8 \mathrm{~kg}$ of soil from the same place where the seeds were collected. Randomized blocks were used as experimental design, with four water treatments (100\%, 75\%, 50\% and 25\% of the field capacity) and six replicates. Plant height, number of leaves and stem diameter were evaluated weekly. At the end of the experimental period, leaf area and specific leaf area ratio, dry matter production of leaves, stem, root and total dry matter production and the biomass allocation for leaves, stem and roots were determined. Water deficit affected plant growth regarded to height, stem diameter and dry matter production for several organs, when grown at levels from $50 \%$ of the field capacity. The number of leaves decreased at all stress levels when compared to $100 \%$ of field capacity treatment. But, the pattern of biomass allocation, root: aerial section ratio, leaf area ratio and specific leaf area were not affected by the stress. The number of leaves was the most sensitive variable to stress. Jatoba seedlings do not paralyze their growth when grown in soil with low water availability in their initial development stage. However, its growth is severely affected by water level below $50 \%$ of water retention capacity in the soil.
\end{abstract}

Keywords: Growth, Dry matter, Root/aerial section ratio and Water deficit.

\footnotetext{
${ }^{1}$ Recebido em 12.02.2009 e aceito para publicação em 18.04.2011.

${ }^{2}$ Programa de Pós-Graduação em Ciências Florestais pela Universidade Federal Rural de Pernambuco, UFRPE, Brasil. E-mail: <h2cn@hotmail.com>e <cellyalmeida@hotmail.com>.

${ }^{3}$ Departamento de Biologia, Universidade Federal Rural de Pernambuco, UFRPE, Brasil. E-mail: < rjmansur1@gmail.com>.

${ }^{4}$ Departamento de Biologia, Universidade Federal de Sergipe, UFS, Brasil. E-mail: <elizaciriaco@hotmail.com>.
}

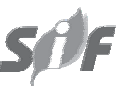

Revista Árvore, Viçosa-MG, v.35, n.3, Edição Especial, p.617-626, 2011 


\section{INTRODUÇÃO}

Atualmente tem-se observado uma crescente conscientização ambiental, seguida de um aumento do interesse em pesquisas com espécies arbóreas nativas, objetivando a recuperação de áreas degradadas e/ou reflorestamento (CARNEIRO, 1995; JOSÉ, 2003; PAIVA, 2003). Entretanto, o custo de tais pesquisas torna-se elevado diante da necessidade de replantio decorrente dos altos índices de mortalidade das mudas. Em alguns casos, isso ocorre devido à falta de conhecimento dos seus aspectos ecofisiológicos, sujeitando-as a áreas propensas a estresses ambientais aos quais não estão adaptadas (CARVALHO FILHO et al., 2003).

As espécies arbóreas brasileiras têm despertado o interesse de vários pesquisadores em demonstrar comportamentos adaptativos que potencializam sua utilização em áreas até então inóspitas para outras espécies, sendo de grande importância silvicultural e econômica. O jatobá (Hymenaea courbaril L.) é um bom exemplo. Relatos afirmando sua vasta distribuição geográfica e sua habilidade de se desenvolver bem em ambientes com diferentes características edafoclimáticas, por essa razão, vem se destacando no cenário científico nacional especialmente por apresentar estratégias adaptativas interessantes para diversas áreas, como: a fisiologia e bioquímica vegetal, a biotecnologia, e o melhoramento genético de plantas (CARVALHO, 1994; PAIVA, 2003).

Outra peculiaridade do jatobá são as baixas exigências nutricionais e hídricas requeridas pela espécie em ambientes naturais, sendo observada sua presença em terrenos que apresentam solos distróficos e bem drenados (LEE;LANGENHEIM, 1975). Lorenzi (1992, 1998, 2002) salienta que ela possui melhor adaptação a formações florestais secas do que às formações úmidas, sendo notada sua ocorrência em áreas de caatinga nordestina, região que tem como principal característica as condições edafoclimáticas adversas à sobrevivência vegetal ante a baixa oferta de água para as plantas, tornando essas áreas sujeitas à seca (ARAÚJO FILHO, 2002; SILVA et al., 2002).

Nogueira et al. (2005) afirmam que a deficiência hídrica afeta todos os aspectos do crescimento e desenvolvimento das plantas, podendo influenciar no alongamento e na diferenciação celular em função da redução na turgescência da célula, resultando na diminuição do desenvolvimento da área foliar, afetando a produção e translocação de fotoassimilados para as novas áreas de crescimento (LUDLOW;MUCHOW, 1990; CARVALHO,2005; LARCHER, 2006). Em reposta final ao estresse, observa-se a redução na produção e alocação de matéria seca por influenciar as trocas gasosas de $\mathrm{CO}_{2}$ e sobre o balanço de carbono (NOGUEIRA et al., 1998, SILVA;NOGUEIRA, 2003).

Diante do exposto, o objetivo deste trabalho foi avaliar o efeito de diferentes regimes hídricos no crescimento e partição de fitomassa seca de mudas de jatobá (Hymenaea courbaril L.).

\section{MATERIAL E MÉTODOS}

O experimento foi desenvolvido em casa de vegetação do Laboratório de Fisiologia Vegetal da Universidade Federal Rural de Pernambuco, entre agosto de 2007 e janeiro de 2008, com período experimental de 105 dias.

As mudas de plantas de jatobá foram produzidas sexuadamente, com sementes procedentes do município de Garanhuns, agreste pernambucano, área de ocorrência da espécie. Para isso, foi realizada escarificação das sementes, manualmente, com auxílio de uma lixa de ferro $n^{\circ} 36$ (CARVALHO, 2003, MOREIRA, 2007). Em seguida, as sementes foram semeadas em bandejas plásticas contendo, como substrato, $17 \mathrm{~kg}$ de solo coletado na profundidade de $0-20 \mathrm{~cm}$, oriundo do local de coleta das sementes, que foi submetido à análise física e de fertilidade (Tabelas 1 e 2). No $20^{\circ}$ dia após a germinação, as plântulas apresentavam grande variação na altura e em média 2 pares de folhas, sendo um par de eófilos e outro de folhas definitivas. Foram selecionadas 24 plântulas uniformes, as quais foram transplantadas para vasos de polietileno contendo $8 \mathrm{~kg}$ do solo anteriormente citado. Os vasos foram cobertos com circunferências de plástico para evitar a perda excessiva de água do substrato por evaporação.

As plantas foram mantidas na capacidade de pote e aclimatadas durante 30 dias. Após esse período, foi dado início a diferenciação dos tratamentos hídricos. A manutenção dos tratamentos foi realizada através da pesagem diária dos vasos e a reposição da água perdida por evapotranspiração, até atingir o peso correspondente a cada tratamento, utilizando-se uma balança de marca Filizola, com capacidade para 15 kg.

O delineamento experimental adotado foi em blocos casualizados, com quatro tratamentos hídricos 100\%, $75 \%$, 50\% e $25 \%$ da capacidade de pote (CP), e seis

Revista Árvore, Viçosa-MG, v.35, n.3, Edição Especial, p.617-626, 2011 
Tabela 1 - Análise da fertilidade do solo coletado em Garanhuns - PE, utilizado no experimento em vasos em casa de vegetação. Table 1 -Fertility analysis of the soil collected in Garanhuns - PE, used in the experiment in vases in a greenhouse.

\begin{tabular}{|c|c|c|c|c|c|c|c|c|c|}
\hline $\mathrm{pH}$ & $\mathrm{P}$ & $\mathrm{Na}^{+}$ & $\mathrm{K}^{+}$ & $\mathrm{Ca}^{+2}+\mathrm{Mg}^{+2}$ & $\mathrm{Ca}^{+2}$ & $\mathrm{Al}^{+3}$ & $\mathrm{H}+\mathrm{Al}$ & C.O. & M.O. \\
\hline (água - 1:2,5) & $\left(\mathrm{mg} / \mathrm{dm}^{3}\right)$ & & & $-(\mathrm{cmol}$ & $\left.n^{3}\right)$ & & & & $\mathrm{g} / \mathrm{kg}$ \\
\hline 5,30 & 30 & 0,46 & 0,29 & 4,00 & 2,50 & 0,20 & 4,19 & 19,08 & 32,90 \\
\hline
\end{tabular}

Analisado no Laboratório de Fertilidade do Solo, Dep. de Agronomia/UFRPE em 09/07/2007.

Analyzed in the Laboratory of Soil Fertility, Dep. of Agronomy/UFRPE in 09/07/2007.

Tabela 2 - Análise física do solo coletado em Garanhuns - PE, utilizado no experimento em vasos em casa de vegetação. Table 2 - Physical analysis of the soil collected in Garanhuns - PE, used in the experiment in vases in a greenhouse.

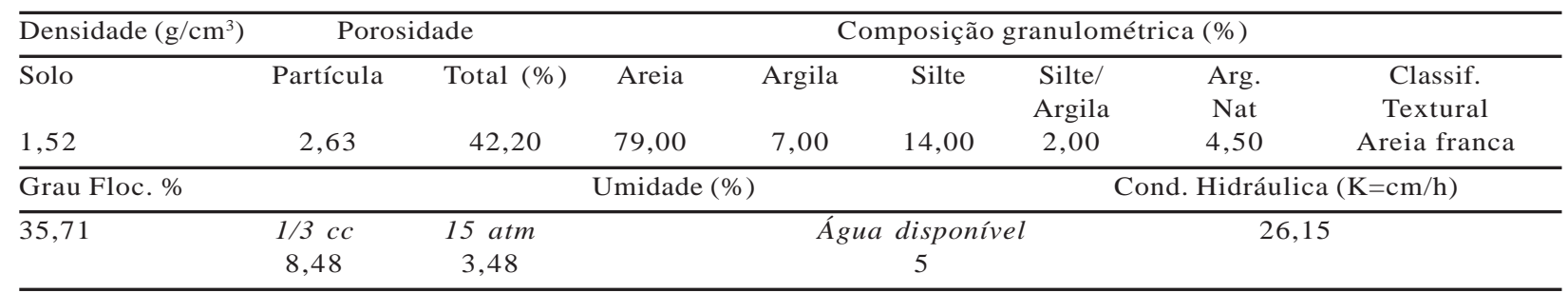

Analisado no Laboratório de Física do Solo, Dep. de Agronomia/UFRPE em 30/07/2007.

Analyzed in the Laboratory of Soil Physics, Dep. of Agronomy/UFRPE in 30/07/2007.

repetições. A capacidade de pote foi determinada pelo método gravimétrico de acordo com a metodologia descrita por Souza et al. (2000).

Durante o período experimental foram mensuradas semanalmente, a altura das plantas (AP), com o auxílio de uma trena, medida da base do caule (previamente marcado) até a inserção da última folha, o diâmetro do caule (DC), com um paquímetro digital de marca Digimess com precisão de $0.002 \mathrm{~mm}$, e a contagem do número de folhas (NF) completamente expandidas. A avaliação da altura das plantas e do diâmetro do caule foi baseada em uma marca indelével feita na base do caule.

Para a determinação da área foliar (AF), foi adotado o método de pesagem de discos foliares proposto por Mielke et al. (1995), utilizando-se um vazador com área conhecida $\left(1 \mathrm{~cm}^{2}\right)$, onde foram destacados discos do limbo foliar das porções basal, mediana e apical. A área foliar foi estimada através da área conhecida dos discos (ACD) foliares destacados, do peso dos discos foliares (PDF) e do peso total das folhas (PTF), tomados em balança analítica. Foi estimada a área foliar total aplicando-se a seguinte fórmula:

$$
A F=\frac{P T F}{P D F^{*} A C D}
$$

A razão de área foliar (RAF) e a área foliar específica (AFE) foram calculadas de acordo com Benincasa (1988), utilizando-se as seguintes equações:

$$
R A F=\frac{A F}{M S T} \text { e } A F E=\frac{A F}{M S F}
$$

sendo: $\mathrm{AF}=$ área foliar; $\mathrm{MST}=$ matéria seca total e FSF= matéria seca das folhas.

No final do período experimental, os órgãos (folhas, caules e raízes) das plantas foram separados, pesados, acondicionados em sacos de papel e levados à estufa de circulação forçada de ar a $65^{\circ} \mathrm{C}$, até atingirem peso constante. Com esses dados, foram calculadas as alocações de biomassa para as folhas (ABF), caule ( $A B C$ ) e raízes (ABR) e determinada a relação raiz/parte aérea $(\mathrm{R} / \mathrm{Pa})$, aplicando-se as fórmulas a seguir (BENINCASA, 1998):

$$
\begin{gathered}
A B F=\frac{M S F}{M S T}, \quad A B C=\frac{M S C}{M S T}, \quad A B R=\frac{M S R}{M S T} \mathrm{e} \\
R / P a=\frac{M S R}{M S F+M S C}
\end{gathered}
$$

sendo: $\mathrm{MSF}=$ matéria seca das folhas, $\mathrm{MSC}=$ matéria seca dos caules, $\mathrm{MSR}=$ matéria seca das raízes e MST= matéria seca total. 
Os dados obtidos foram submetidos à análise de variância para detectar possíveis efeitos dos tratamentos sobre as variáveis analisadas (FERREIRA, 2000), utilizando-se o software ESTAT (Sistemas para análises estatísticas, UNESP - Jatobicabal) versão 2.0. Para a normalização, os dados de número de folhas foram transformados para $\sqrt{X+0,5}$ (ZAR, 1999), sendo as médias comparadas entre si pelo teste de Tukey, a 5\% .

\section{RESULTADOS E DISCUSSÃO}

\subsection{Avaliação biométrica}

As análises estatísticas evidenciaram diferenças significativas entre os tratamentos hídricos em todas as variáveis biométricas.

Na Figura 1, pode-se observar que o estresse hídrico afetou significativamente a altura das plantas a partir $49^{\circ}$ dia após a diferenciação. As plantas do tratamento controle (100\% da CP) apresentaram os maiores valores de altura (em média 62,6 cm) quando comparadas com os demais tratamentos hídricos. Contudo, não foi observada diferenças estatísticas entre as plantas sob estresse semimoderado e moderado (75\% e 50\% da CP), apresentando similaridade no crescimento (em média $51,0 \mathrm{~cm}$ e 49,0 cm, respectivamente) durante o período avaliado. Já as plantas submetidas a estresse severo (25\% da CP) tiveram seu crescimento em altura reduzido em 42,17\%, apresentando os menores valores (em média $32,8 \mathrm{~cm}$ ) quando comparado com o tratamento controle.

Quanto ao número de folhas, verificou-se que o déficit hídrico reduziu a emissão de novas folhas a partir do $28^{\circ}$ dia após a diferenciação dos tratamentos (DAD) (Figura 1). As plantas submetidas a $100 \%$ da CP apresentaram as maiores médias de emissão de folhas (20,4 folhas), diferenciando-se estatisticamente dos demais tratamentos. Não foram observadas diferenças significativas entre os tratamentos $75 \%$ e $50 \%$ da CP. O déficit hídrico reduziu a emissão de folhas ( 7 folhas) no tratamento $25 \%$ em até $65,7 \%$, diferenciando-o estatisticamente dos demais tratamentos hídricos. Esta variável, ao menos em parte, pode ser o reflexo de menor taxa de divisão celular, reduzindo assim o aparecimento de novas folhas, a qual aparentemente se tornou mais lenta nas plantas sob estresse hídrico severo. Os resultados de número de folhas corroboram com os encontrados por Silva e Nogueira (2003)estudando o efeito do estresse hídrico sob o crescimento de quatro espécies lenhosas. As autoras afirmam que as mudas de Mimosa caesalpiniifolia, Prosopis juliflora e Tabebuia áurea apresentaram redução na emissão de novas folhas após a indução ao estresse hídrico, no entanto essa redução não foi suficiente para interromper o aparecimento de novas folhas. Já com Enterolobium contortisilicum, as autoras evidenciaram que a restrição hídrica promoveu abscisão foliar, ocasionando redução na AF, RAF e AFE.

Com relação ao diâmetro do caule, diferenças significativas foram observadas a partir do $49^{\circ} \mathrm{DAD}$, notando-se um comportamento estatístico semelhante com os dados de altura, onde os tratamentos $100 \%$, 75\% e 50\% da CP não apresentaram diferenças estatísticas significativas entre si. Da mesma forma, o tratamento $25 \%$ não diferiu significativamente dos tratamentos $75 \%$ e $50 \%$, diferindo-se estatisticamente apenas do tratamento $100 \%$ da CP (Figura 1). As reduções no diâmetro do caule foram de até $16,3 \%$ para $75 \%$ da CP, $20,7 \%$ para $50 \%$ da CP e $31,0 \%$ para $25 \%$ da CP, em relação às plantas cultivadas com 100\% CP.

De forma geral, os valores biométricos encontrados corroboram com os de Carvalho Filho et al. (2003), Melo et al. (2004) e Almeida et al. (2005), estudando o crescimento de mudas da mesma espécie sob condições hídricas normais, havendo diferença apenas dos valores obtidos pelas plantas submetidas a $25 \%$ da CP encontrados nesta pesquisa, evidenciando a ação do estresse hídrico na redução da biometria dessas plantas. Neste trabalho, o número de folhas foi mais afetado do que o crescimento em altura e diâmetro do caule. Segundo Cairo (1995), a primeira consequência fisiológica para as plantas submetidas a estresse hídrico é a redução ou a interrupção dos ritmos de crescimento, devido à redução na diferenciação celular, influenciada pela restrição hídrica imposta pelo tratamento adotado (SILVA;NOGUEIRA, 2003).

Resultados semelhantes foram encontrados por Silva et al. (2002) trabalhando com plantas jovens de Melaleuca alternifolia Cheel, e Figueirôa et al. (2004), com plantas jovens de Myracrodruon urundeuva Allemão, submetidas a diferentes tratamentos hídricos, os quais verificaram reduções na altura, número de folhas e diâmetro do caule das plantas sob estresse.

\subsection{Avaliação da matéria seca}

De maneira semelhante às avaliações biométricas, o estresse hídrico também afetou, de forma significativa, a produção de matéria seca das folhas (MSF), caules (MSC), raízes (MSR) e total (MST).

Revista Árvore, Viçosa-MG, v.35, n.3, Edição Especial, p.617-626, 2011 


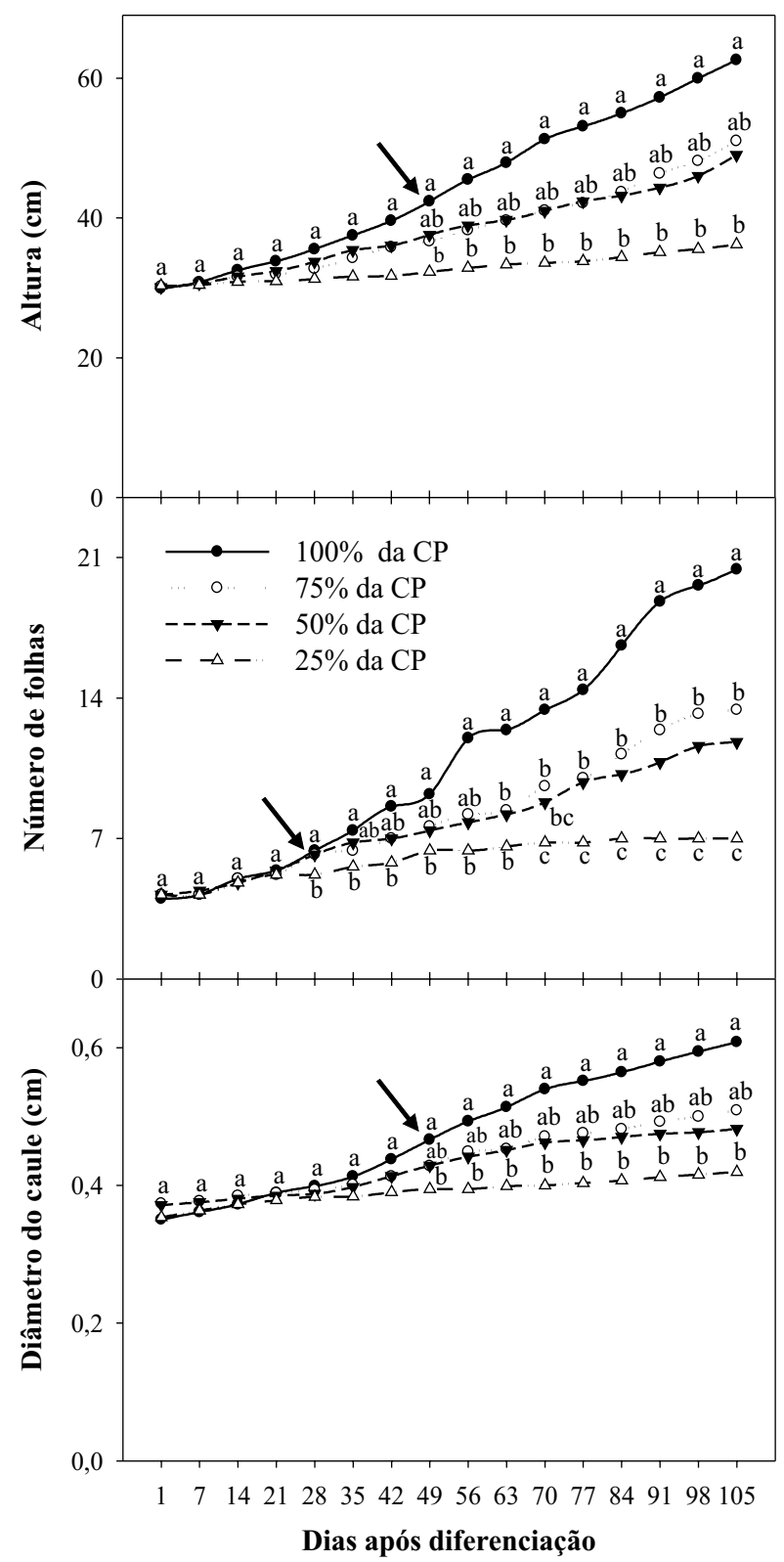

Figura 1 - Altura, número de folhas e diâmetro do caule de mudas de jatobá (Hymenaea courbaril L.) em diferentes níveis de água no solo. Médias seguidas de mesma letra não diferiram entre si, pelo teste de Tukey, $(\mathrm{p}<0,05)$. As setas indicam diferença significativa entre os tratamentos estudados.

Figure 1 - Plant height, number of leaves and stem diameter of jatobá seedlings (Hymenaea courbaril L.) at different water levels in the soil. Means followed by the same letters do not differ by Tukey test $(P<0.05)$. The arrows indicate significant difference between the studied treatments and the asterisks.
Foi observado um comportamento similar entre os valores obtidos para MSF, MSC e MST, tendo o tratamento $100 \%$ da CP como detentor das maiores médias, respectivamente 6,1 g, 7,2 g e 18,6 g (Figura 2). Os menores valores foram observados no tratamento $25 \%$ da CP, sendo 1,4 g, 2,1 g e 5,5 g, respectivamente, obtendo reduções na ordem de 77,0\%, 70,8\% e 70,4\% quando comparado com o tratamento $100 \%$ da CP. O tratamento $75 \%$ da CP não apresentou diferenças significativas com nenhum outro tratamento hídrico.

Já na MSR, os maiores valores foram 5,3 g e 4,8 g nos tratamentos $100 \%$ e $75 \%$ da CP, respectivamente (Figura 2). As plantas do tratamento 50\% da CP apresentaram comportamento intermediário, não se diferenciando estatisticamente dos demais. Já o tratamento 25\% da CP apresentou os menores valores, reduzindo sua MSR em 62,8\% em relação ao tratamento $100 \%$ da CP.

Relativo a esses resultados, Costa (2004) e Almeida et al. (2005) obtiveram valores semelhantes aos desta pesquisa, utilizando plantas em condições hídricas normais, corroborando a produção de matéria seca pelas plantas submetidas a 100\% da CP. Já Silva e Nogueira (2003), avaliando o crescimento de Mimosa caesalpiniifolia, Enterolobium contortisiliquum, Prosopis juliflora e Tabebuia aurea sob estresse hídrico em casa de vegetação, afirmam que o estresse hídrico afetou significativamente na MSF, MSR e MST em todas as espécies avaliadas. Griffiths e Parry (2002) sugeriram que a redução da produção de fitomassa seca, em plantas sujeitas a estresse hídrico, se torna mais visível na medida em que a exposição ao estresse é mais prolongada, como foi observado neste trabalho.

\subsection{Avaliação da alocação de biomassa e relação raiz/ parte aérea}

De acordo com Benincasa (1988), a alocação de biomassa nos diversos órgãos da planta permite inferir processos fisiológicos como a translocação orgânica, e sua análise facilita bastante a compreensão do comportamento vegetal em termos de produtividade.

Neste estudo, as análises estatísticas indicaram que não houve diferenças significativas entre as variáveis avaliadas (ABF, ABC, ABR), comprovando que o estresse hídrico não afetou a alocação de fitomassa nos tratamentos estudados (Figura 3). 


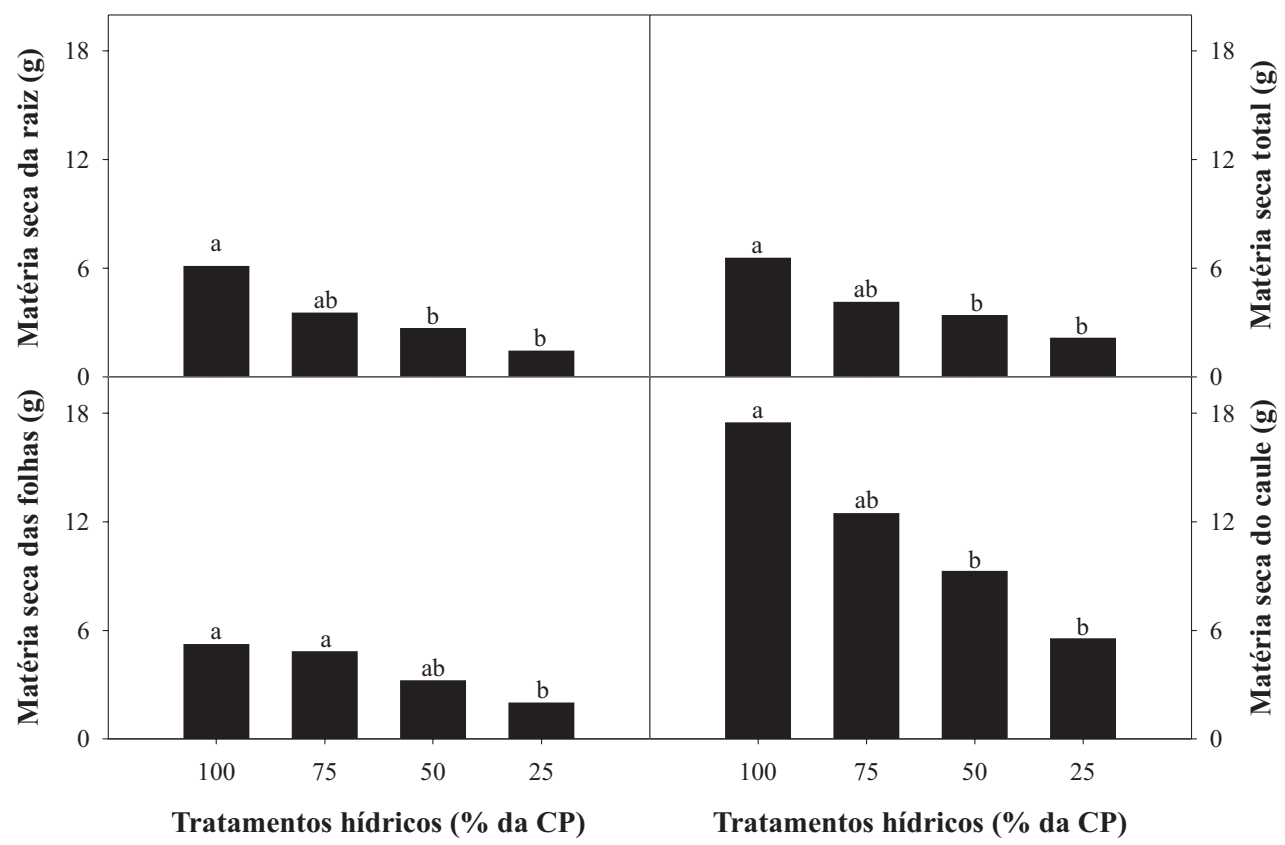

Figura 2 - Valores médios da matéria seca das folhas (MSF), dos caules (MSC), das raízes (MSR) e total (MST) de mudas de jatobá (Hymenaea courbaril L.) em diferentes níveis de água no solo. Médias seguidas de mesma letra não diferiram entre si, pelo teste de Tukey $(\mathrm{p}<0,05)$.

Figure 2 - Mean values of the leaf (LDM), stem (SDM), roots (RDM) and total dry matter (TDM) of jatobA seedlings (Hymenaea courbaril L.) at different water levels in the soil. Mean values followed by the same letter did not differ among each other by Tukey test $(P<0.05)$.

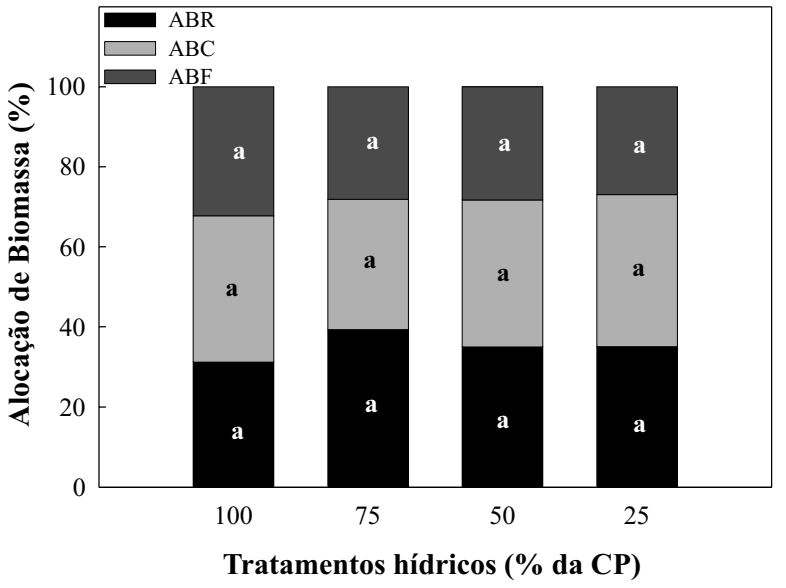

Figura 3 - Alocação de biomassa para as folhas (ABF), caule (ABC) e raízes (ABR) de mudas de jatobá (Hymenaea courbaril L.) em diferentes níveis de água no solo. Médias seguidas de mesma letra não diferiram entre si, pelo teste de Tukey $(\mathrm{p}<0,05)$.

Figure 3 - Biomass allocation to leaves (BAL), stem (BAS) and roots (BAR) of jatobá seedlings (Hymenaea courbaril $L$.) at different water levels in the soil. Means followed by the same letters not differ by Tukey test $(P<0.05)$.
Sobre os resultados obtidos, Aidar et al. (2002) e Santos (2002), estudando Hymenaea courbaril var. Stilbocarpa, encontraram valores que concordam com os encontrados neste estudo. Os autores atribuem esse comportamento às baixas taxas de crescimento apresentados pela espécie, propiciando uma translocação e acúmulo de fotoassimilados mais eficiente, mesmo em condições adversas de luminosidade, concentração de $\mathrm{CO}_{2}$ e deficiência hídrica. Já Lovelock et al. (1998), estudando o crescimento de espécies arbóreas tropicais submetidas a restrições hídricas, salientam que uma das possíveis explicações para a similaridade na alocação de biomassa de algumas espécies florestais ocorre em virtude das baixas taxas fotossintéticas e transpiratórias apresentadas por essas espécies. Os autores ressaltam que, de acordo com o grupo sucessional a que a espécie pertence, os valores de alocação de biomassa podem apresentar maior semelhança, independente dos tratamentos hídricos, principalmente nas espécies que possuem hábitos de crescimento lento, citando como exemplo as secundárias tardias e climácicas, como é o caso do jatobá, que se enquadra com espécie climácica

Revista Árvore, Viçosa-MG, v.35, n.3, Edição Especial, p.617-626, 2011 
na sucessão ecológica (LORENZI, 1998; 2002; CARVALHO 2003), sendo essa característica uma possível explicação da similaridade nos valores obtidos para alocação de biomassa neste estudo.

Quanto à relação raiz/parte aérea, verifica-se que não houve diferenças significativas entre os tratamentos aplicados (Tabela 3). Uma das razões para tal comportamento pode estar ligada ao equilíbrio no crescimento entre a raiz e a parte aérea dessas plantas, não havendo necessidade de investirem especificamente no seu aprofundamento radicular, fato corroborado por Cairo (1992) e Leles et al. (1998), também estudando plântulas de Hymenaea courbaril submetidas a diferentes disponibilidades de água no solo e atribuindo tal equilíbrio à lentidão no crescimento apresentado pela espécie.

\subsection{Avaliação da área foliar, razão de área foliar e área foliar específica}

O estresse aplicado foi suficiente para causar alterações significativas na área foliar (Tabela 4). O tratamento $100 \%$ da CP proporcionou a maior média

Tabela 3 - Valores médios da relação raiz/parte aérea (R/ $\mathrm{Pa}$ ) de mudas de jatobá (Hymenaea courbaril L.) em diferentes níveis de água no solo.

Table 3 - Mean values of the root:aerial section ratio (R:S) of jatobá seedlings (Hymenaea courbaril L.) at different water levels in the soil.

\begin{tabular}{|c|c|}
\hline Tratamentos & Relação raiz/parte aérea \\
\hline $100 \%$ da CP & 0,461 \\
\hline $75 \%$ da CP & 0,657 \\
\hline $50 \%$ da CP & 0,566 \\
\hline $25 \%$ da CP & 0,550 \\
\hline
\end{tabular}

Médias seguidas de mesma letra não diferiram entre si, pelo teste de Tukey $(\mathrm{p}<0,05)$.

Averages values following by the same letter had not differed among them, by Tukey test $(p<0.05)$ de área foliar com 758,6 cm² os tratamentos 75\% e $50 \%$ da CP tiveram comportamento intermediário e não se diferenciaram dos demais tratamentos. Já o tratamento $25 \%$ da CP teve sua área foliar reduzida em 70,1\%, quando comparado ao tratamento $100 \%$ da CP. Esses resultados foram semelhantes aos encontrados por Cairo (1992) e Lovelock et al. (1998) estudando espécies florestais lenhosas. Os autores afirmaram que a área foliar é extremamente afetada pela quantidade de água disponível no solo.

Ellswort et al. (1995) e Van Volkenburgh (1999) asseguram que a área foliar apresenta um papel fundamental na determinação da quantidade de luz que a planta intercepta, na fixação de carbono, na perda de água, e até da produtividade do ecossistema. Larcher (2006) complementa que a área foliar está relacionada ao desenvolvimento foliar, podendo estar associada à redução no tamanho das folhas ou à menor produção delas, consequentemente a área de captação de luz, as reações fotossintéticas e as trocas gasosas são severamente influenciadas (LARCHER, 2006).

Apesar de apresentarem diferenças significativas na área foliar, os valores da razão de área foliar (RAF) e área foliar específica (AFE) não apresentaram diferenças significativas, sugerindo que o estresse adotado não foi o suficiente para causar diferenças significativas entre os tratamentos, resultados corroborados por Silva e Nogueira (2003) ao estudarem quatro espécies lenhosas cultivadas sob estresse hídrico. Dessa forma, pode-se afirmar que a redução da área foliar deve-se, pelo menos em parte, à redução na emissão de novas folhas nos tratamentos mais severos.

Figuerôa et al. (2004) afirmam que a umidade relativa do ambiente é que determina a área foliar de uma planta, sendo maior em ambientes úmidos e menores em ambientes áridos. Esta característica é uma importante

Tabela 4 - Média da área foliar, razão de área foliar (RAF) e área foliar específica (AFE) em mudas de jatobá (Hymenaea courbaril L.) em diferentes níveis de água no solo.

Table 4 - Means of the leaf foliar area, leaf area ratio (LAR) and specific foliar area (SFA) in jatobá seedlings (Hymenaea courbaril L.) at different water levels in the soil.

\begin{tabular}{lccc}
\hline Tratamentos & Área foliar $\left(\mathrm{cm}^{2}\right)$ & RAF $\left(\mathrm{cm}^{2} \cdot \mathrm{g}^{-1} \mathrm{MS}\right)$ & AFE $\left(\mathrm{cm}^{2} \cdot \mathrm{g}^{-1} \mathrm{MS}\right)$ \\
\hline $100 \%$ da CP & $758,63 \mathrm{a}$ & 30,52 a & 100,00 a \\
$75 \%$ da CP & $477,05 \mathrm{ab}$ & 46,21 a & 144,91 a \\
$50 \%$ da CP & $378,70 \mathrm{ab}$ & 27,98 a & 82,64 a \\
$25 \%$ da CP & $226,95 \mathrm{~b}$ & 39,53 a & 125,00 a \\
\hline
\end{tabular}

Médias seguidas de mesma letra não diferiram entre si, pelo teste de Tukey $(\mathrm{p}<0,05)$.

Averages values following by the same letter had not differed among them, by Tukey test $(p<0.05)$. 
defesa contra a perda excessiva de água, e a diminuição da área foliar está entre as várias características xeromórficas identificadas em vegetais sob déficit hídrico (VILLAGRA; CAVAGNARO, 2006).

\section{CONCLUSÕES}

1. A produção de matéria seca em mudas de jatobá é a variável mais sensível à deficiência hídrica.

2. Níveis abaixo de $50 \%$ da capacidade de retenção de água no solo restringem significativamente o crescimento de mudas de jatobá (Hymenaea couribaril).

\section{AGRADECIMENTOS}

Ao CNPq, pela concessão da bolsa.

\section{REFERÊNCIAS}

AIDAR, M. P. M. et al. Effect of atmospheric $\mathrm{CO}_{2}$ enrichment on the establishment of seedlings of jatobá, Hymenaea courbaril L. (Leguminosae, Caesalpinioideae). Biota Neotropica, v.2, n.1, p.79-88, 2002.

ALMEIDA, S. M. Z. et al. Alterações morfológicas e alocação de biomassa em plantas jovens de espécies florestais sob diferentes condições de sombreamento. Ciência Rural, v.35, n.1, p.62-68, 2005.

ARAÚJO FILHO, J. A. Histórico do uso dos solos da caatinga. In: ARAÚJO, Q. R. 500 anos de uso do solo no Brasil. Bahia: UESC, 2002. p.329-338.

BEninCASA, M. M. P. Análise de crescimento de plantas. Jaboticabal: FUNEP, 1988. p.42.

CAIRO, P. A. R. Aspectos biofísicos e metabólicos de plantas jovens de espécies florestais associados à disponibilidade de água no solo. 1992. 124f. Dissertação (Mestrado em Fisiologia Vegetal) - Escola Superior de Agricultura de lavras, Lavras, 1992.

CAIRO, P. A. R. Curso básico de relações hídricas de plantas. Vitória da Conquista: UESB, 1995. 32p.
CARneiro, J. G. A. Produção e controle de qualidade de mudas florestais. Curitiba: UFPR/FUPEF/Campos: UENF, 1995. p.451.

CARVALHO, C. J. R. Respostas de plantas de Schizolobium amazonicum (S. parahyba var. amazonicum) e Schizolobium parahyba (Schizolobium parahybum) à deficiência hídrica. Revista Árvore, v.29, n.6, p.907-914, 2005.

CARVALHO FILHO, J. L. S. et al. Produção de mudas de jatobá (Hymenaea courbaril L.) em diferentes ambientes, recipientes e composições de substratos. Cerne, v.9, n.1, p.109-118, 2003.

\section{CARVALHO, P. E. R. Espécies florestais brasileiras: recomendações silviculturais, potencialidades e uso da madeira. Brasília: Embrapa/CNPF, 1994. 640p.}

CARVALHO, P. E. R. Espécies arbóreas brasileiras. Brasília: Embrapa Informação Tecnológica/ Colombo: Embrapa Florestas, 2003. v.1.1039p.

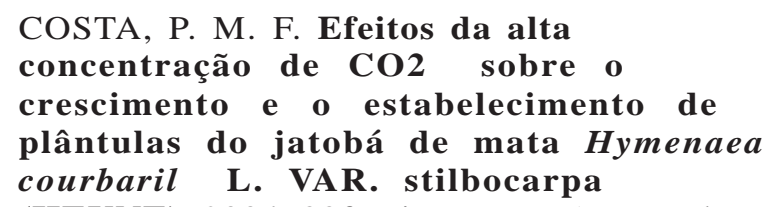
Biologia Celular e Estrutural) - Instituto de Biologia, UNICAMP, Campinas, 2004.

ELLSWORTH, D. S. et al. Leaf and canopy responses to elevated $\mathrm{CO} 2$ in a pine forest under free air CO2 enrichment. Oecologia, v.104, p.139-146, 1995.

FERREIRA, P. V. Estatística experimental aplicada à agronomia. 3.ed. Maceió: EDUFAL, 2000. 419p.

FIGUEIRÔA, J. M.; BARBOSA, D. C. A.; SIMABUKURO, E. A. Crescimento de plantas jovens de Myracrodruon urundeuva Allemão (Anacardiaceae) sob diferentes regimes hídricos. Acta Botanica Brasílica, v.18, n.3, p.573-580, 2004.

GRIFFITHS, H. \& PARRY, M. A. J. Plant responses to water stress. Annals of Botany, v.89, p.801-802, 2002. 
JOSÉ, A. C. Utilização de mudas de espécies florestais produzidas em tubetes e sacos plásticos para revegetação de áreas degradadas. 2003. 101f. Dissertação (Mestrado em Engenharia Florestal) - Universidade Federal de Lavras, Lavras, 2003.

LARCHER, W. Ecofisiologia vegetal. São Carlos, Rima, 2006.

LEE, Y. T.; LANGENHEIM, J. H. Systematics of the genus Hymenaea (Leguminosae: Caesalpinioideae, Detarieae). Berkeley: University of California, 1975. 190 p. (Publication in Botany, 69).

LELES, P. S. S.; CARNEIRO, J. G. A.; BARROSO, D. G. Comportamento de mudas de Hymenaea courbaril L. var. stilbocarpa (Hayne) e Apuleia leiocarpa (Vog.) Macbr. produzidas sob três regimes de irrigação. Revista Árvore, v.22, n.1, p.11-19, 1998.

LORENZI, H. Árvores brasileiras Nova Odessa: Instituto Plantarum, 1992. v.1. 384p.

LORENZI, H. Árvores brasileiras: Manual de identificação e cultivo de plantas arbóreas nativas do Brasil. 2.ed. Nova Odessa: Instituto Plantarum, 1998. v.1. 352p.

LORENZI, H. Plantas medicinais no Brasil: nativas e exóticas cultivadas. Nova Odessa: Instituto Plantarum, 2002. 512p.

LOVELOCK, C. E. et al. Responses of communities of tropical tree species in water-limited.

Oecologia, v.116, p.207-218, 1998.

LUDLOW, M. M.; MUCHOW, R. C. A critical evaluation of traits for improving crop yields in water-limited. Advances in Agronomy, v.43, p.107-153, 1990.

MELO, M. G. G.; MENDONÇA M. S.; MENDES, A. M. S. Análise morfológica de sementes, germinação e plântulas de jatobá (Hymenaea intermedia Ducke var. adenotricha (Ducke) Lee \& Lang.) (Leguminosae-Caesalpinioideae). Acta Amazônica, v.34, n.1, p.9-14, 2004.
MIELKE, M. S. et al. Comparação de métodos de laboratório e de campo para estimativa da área foliar em fruteiras silvestres. Scientia Agricola, v.52, n.1, p.82-88, 1995.

MOREIRA, M. A. T. et al. Superação da dormência em sementes de jatobá (Hymenaea courbaril L.). Disponível em: http:// www.dcf.ufla.br/Cerne/revistav2n1-1996/ TENYARTJ.PDF. Acessado em 22 de out. de 2007.

NOGUEIRA, R. J. M. C.; BARBOSA, D. C.A.; MORAES, J. A. P. V. Trocas gasosas e relações hídricas em plantas jovens envasadas de três espécies da caatinga, submetidas à deficiência de água. Phyton, v.62, n.1/2, p.37-46, 1998.

NOGUEIRA, R. J. M. C.; ALBUQUERQUE, M. B.; SILVA, E. C. Aspectos ecofisiológicos da tolerância à seca em plantas da caatinga. In: NOGUEIRA, R. J. M. C. et al. Estresses ambientais: danos e benefícios em plantas. Recife: Universidade Federal de Pernambuco, 2005. p.22-31.

PAIVA, H. N.; VITAL, B. R. Escolha da espécie florestal. Viçosa, MG: Universidade Federal de Viçosa, 2003. 42p. (Cadernos Didáticos, 93)

SANTOS, H. P. Importância ecofisiológica da reserva de xiloglucano e o controle de sua mobilização em cotilédones de Hymenaea courbaril L. 2002. 153f. Tese (Doutorado em Biologia Vegetal) - Instituto de Biologia/UNICAMP, Campinas, 2002.

SILVA, E. C. et al. Comportamento estomático e potencial da água da folha em três espécies lenhosas cultivadas sob estresse hídrico. Acta Botânica Brasilica, v.17, n.2. p.231-246, 2003.

SILVA, E. C.; NOGUEIRA, R. J. M. Crescimento de quatro espécies lenhosas cultivadas sob estresse hídrico em casa-de-vegetação. Revista Ceres, v.50, n.288, p.203-217, 2003.

SILVA, S. R. S. et al. Efeito do estresse hídrico sobre características de crescimento e a produção de óleo essencial de Melaleuca alternifolia Cheel. Acta Scientiarum, v.24, n.5, p.1363-1368, 2002. 
SOUZA, C. C. et al. Avaliação de métodos de determinação de água disponível e manejo da irrigação em terra roxa sob cultivo de algodoeiro herbáceo.

Revista Brasileira de Engenharia

Agrícola e Ambiental, v.4, n.3, p.338-342, 2000.

van VOLKENBURGH, E. Leaf expansion-an integrating plant behavior. Commissioned review. Plant, Cell and Environment, v.22, p.1463-1473, 1999.
VILLAGRA, P. E.; CAVAGNARO, J. B. Water stress effects on the seedling growth of Prosopis argentina and Prosopis alpataco. Journal of Arid Environments, v.64, p.390-400, 2006.

ZAR, J. H. Biostatiscal analyses. New Jersey: Prentice Hall, 1999. 663p. 